\title{
Association between ovarian reserve and preeclampsia: a cohort study
}

\author{
Hadi Erfani ${ }^{1,2}$, Maryam Rahmati ${ }^{2,3}$, Mohammad Ali Mansournia ${ }^{3}$, Fereidoun Azizi ${ }^{2,4}$, Seyed Ali Montazeri²,
} Alireza A. Shamshirsaz ${ }^{1}$ and Fahimeh Ramezani Tehrani ${ }^{*}$

\begin{abstract}
Background: The risk of cardiovascular disease in women increases after menopause. It has been shown that women with lower pre-menopausal ovarian reserve may experience increased cardiovascular risk. We sought to determine whether there is any association between ovarian reserve, as assessed by Anti-Mullerian hormone (AMH), and preeclampsia (PE).

Methods: Subjects of this study were selected from among participants of the Tehran Lipid and Glucose Study (TLGS), a population-based cohort with a 15-year follow-up (1998-2014). Out of 2412 women aged 20-50 years, there were 781 women who met eligibility criteria, including having comprehensive data on their reproductive assessment and ovarian reserve status, identified based on age-specific AMH levels according to the exponentialnormal three-parameter model that was measured before pregnancy.

There were 80 and 701 participants in the preeclampsia and non-PE groups, respectively. The association between dichotomous outcome variable PE and age-specific AMH quartiles was evaluated using pooled logistic regression.

Results: PE was observed in 23 (11.1\%), 12 (6.4\%), 26 (13.3\%) and 19 (10\%) women in the 1st, 2nd, 3rd and 4th quartiles of pre-pregnancy age-specific $\mathrm{AMH}$, respectively $(P=0.16)$. Median and inter-quartile range of serum $\mathrm{AMH}$ levels was $1.05(0.36-2.2) \mathrm{mg} / \mathrm{L}$ in women who experienced PE compared with $0.85(0.28-2.1) \mathrm{mg} / \mathrm{L}$ in women with normotensive pregnancies $(P=0.53)$. Based on the pooled logistic regression analysis, the effect of age-specific AMH quartiles on PE progression (adjusted for age, BMI, smoking status, and family history of hypertension) were

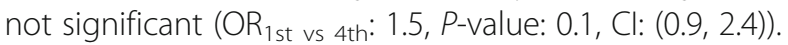

Conclusions: Age-specific AMH may not be a suitable marker for prediction of PE. Further longitudinal studies, considering pre-conception measurement of $\mathrm{AMH}$, are recommended for better interpretation of the association between ovarian reserve status and PE.
\end{abstract}

Keywords: Anti-Mullerian hormone, Ovarian reserve, Pre-Eclampsia

\section{Background}

Pregnancy induced hypertension/Pre-Eclampsia (PE) is a major cause of maternal and fetal morbidity and mortality. Hypertensive disorders of pregnancy occur in 3-10\% of all pregnancies, with preeclampsia playing a role in approximately $10 \%$ of maternal deaths in the United

\footnotetext{
* Correspondence: ramezani@endocrine.ac.ir; framezan@post.harvard.edu Presentation at conference: This study was presented at the 2019 Annual Meeting of Society for Maternal-Fetal medicine (Pregnancy Meeting ${ }^{\mathrm{TM}}$ ) Las Vegas, Nevada, U.S.A.

${ }^{2}$ Reproductive Endocrinology Research Center, Research Institute for Endocrine Sciences, Shahid Beheshti University of Medical Sciences, 24 Parvaneh, Yaman Street, Velenjak, P.O. Box:19395-4763, Tehran 1985717413, Iran

Full list of author information is available at the end of the article
}

States [1-3]. Thus, the identification of risk factors for hypertensive disease in pregnancy is essential, and might offer a better understanding of the underlying pathophysiology of this condition.

Anti-Mullerian Hormone (AMH) is a highly glycosylated homodimeric glycoprotein which is produced in the somatic cells of the ovaries; a member of the transforming growth factor beta family secreted by the granulosa cells of the ovarian follicles [4]. Previous studies suggest that serum AMH is a good indicator of ovarian follicular reserve and a single measurement can both reflect ovulatory decline and reliably predict the age of menopause [5-8]. In addition several studies have addressed the

(c) The Author(s). 2019 Open Access This article is distributed under the terms of the Creative Commons Attribution 4.0 International License (http://creativecommons.org/licenses/by/4.0/), which permits unrestricted use, distribution, and reproduction in any medium, provided you give appropriate credit to the original author(s) and the source, provide a link to the Creative Commons license, and indicate if changes were made. The Creative Commons Public Domain Dedication waiver (http://creativecommons.org/publicdomain/zero/1.0/) applies to the data made available in this article, unless otherwise stated. 
potential association of low ovarian reserve with cardiovascular risks [9-11]. A study by de Kat et al., in 2017 indicated that $\mathrm{AMH}$ trajectories in women are associated with cardiovascular risks; therefore, the decline of circulating AMH levels may be part of the pathophysiology of increased cardiovascular risk attributed to the early menopause [12]. In another study Kim et al., proposed belief that in midlife women with type 1 diabetes $\mathrm{AMH}$ has slight but significant association with subclinical measures of atherosclerosis [13].

These observations suggest the possibility that serum AMH levels might also be predictive of pregnancy induced hypertension/ PE, a pre-menopausal cardiovascular disease of major clinical importance, particularly since women with $\mathrm{PE}$ are at risk for later cardiovascular disease. Several previous studies have suggested a link between AMH levels and PE [14-16].

In this study, we sought to determine whether ovarian reserve status, as indicated by serum concentrations of $\mathrm{AMH}$ or age specific AMH predicts PE using data from a 15-year population-based cohort.

\section{Methods}

\section{Study subjects}

The ethics committee of the Research Institute for Endocrine Sciences approved the study (IR.SBMU.ENDOCRINE.REC.1398.009) and written informed consent was obtained from all subjects before initiation of the study. Data was obtained from the Tehran Lipid and Glucose Study (TLGS), an ongoing prospective study in Tehran, Iran, initiated in 1998 [17]. To date TLGS has completed five phases at 3-year intervals (phase 1: 19992001, phase 2: 2002-2005, phase 3: 2005-2008, phase 4: 2008-2011 and phase 5: 2011-2014). Current data are available for five phases, including baseline and four follow-ups. TLGS involves 15,005 subjects, aged $\geq 3$ years, who were selected from a geographically defined population using multi-stage cluster sampling. At the time of data collection (both base line and follow-ups) women were interviewed by trained personnel using pretested questionnaires including information on demographic and lifestyle variables, smoking habits, various risk factors for non-communicable diseases, family history of hypertension and medical and reproductive histories; all clinical, and anthropometric parameters included weight and Waist Circumference (WC) were measured by interviewers, as well. WC was measured with an unstretched tape measure at the level of the umbilicus, without any pressure to the body surface. Systolic Blood Pressure (SBP) and Diastolic Blood Pressure (DBP) were measured twice in a seated position after a 15-min rest period. At each visit, women were asked about having any experience of $\mathrm{PE}$, using a validated self-reporting questionnaire $[18,19]$; when the women were not sure of the diagnosis their medical documents were referred to.

A blood sample was taken from all participants between 7:00 am and 9:00 am after a 12-h overnight fast. Biochemical assessments were performed at the TLGS research laboratory on the day of blood collection. Back up samples were stored at -80 degree of centigrade.

Triglyceride (TG) levels were assayed using glycerol phosphate. Total Cholesterol (TC) was assayed using the enzymatic colorimetric method with cholesterol esterase and cholesterol oxidase. The level of High-density Lipoprotein Cholesterol (HDL-C) was measured after precipitation of the apolipoprotein B (apo B)-containing lipoproteins with phosphotungstic acid. We used a modified Friedewald equation to calculate Low-density Lipoprotein Cholesterol (LDL-C). Fasting plasma glucose (FPG) and 2-h postchallenge plasma glucose ( $2 \mathrm{~h}$-PCPG) were measured using an enzymatic colorimetric method with glucose oxidase; inter- and intra-assay Coefficients of Variations (CVs) at baseline and follow-up phases were both $<2.3 \%$. All metabolic analyses were performed using related kits and a Selecta 2 autoanalyzer. Intra-assay and inter-assay CVs for TG, TC, HDL-C, and LDL-C were less than 2.1, 1.9, 3, and $3 \%$, respectively.

Serum concentration of AMH was measured in stored samples at the time of recruitment by the two-site enzyme immunoassay (EIA) method using Gen II kit (intra- and inter-assay CVs were 1.9 and 2.0\%, respectively) and sunrise ELISA reader. More details on measurements have been previously published elsewhere [10].

Our study population included all women who met the following eligibility criteria: [1] age between 20 and 50 years, [2] having regular cycles at the time of enrollment, [3] having history of normal fertility and delivery (at least one term pregnancy within 1 year of stopping contraception) without having a history of pregnancy after Assisted Reproductive Technologies (ART), and [5] having no history of endocrine problems, hysterectomy, oophorectomy, or any other surgeries on ovaries. There were 1015 subjects who met the inclusion criteria; after exclusion of those with uncertain data regarding history of PE, those with history of PE or chronic hypertension at initiation of the study $(n=112)$, data of 781 women remained for inclusion in the present study (Fig. 1).

\section{Definitions}

The normal-based methodology used to calculate agespecific AMH percentiles has been described previously in detail by Altman and Chitty [20] and Royston and Wright [21, 22]. Age-specific AMH was estimated using the exponential-normal three-parameter model. Our previous study depicts cut-off values for women of each specific age for defining the age-specific $\mathrm{AMH}$ quartiles [23]. PE was defined based on the international standard 


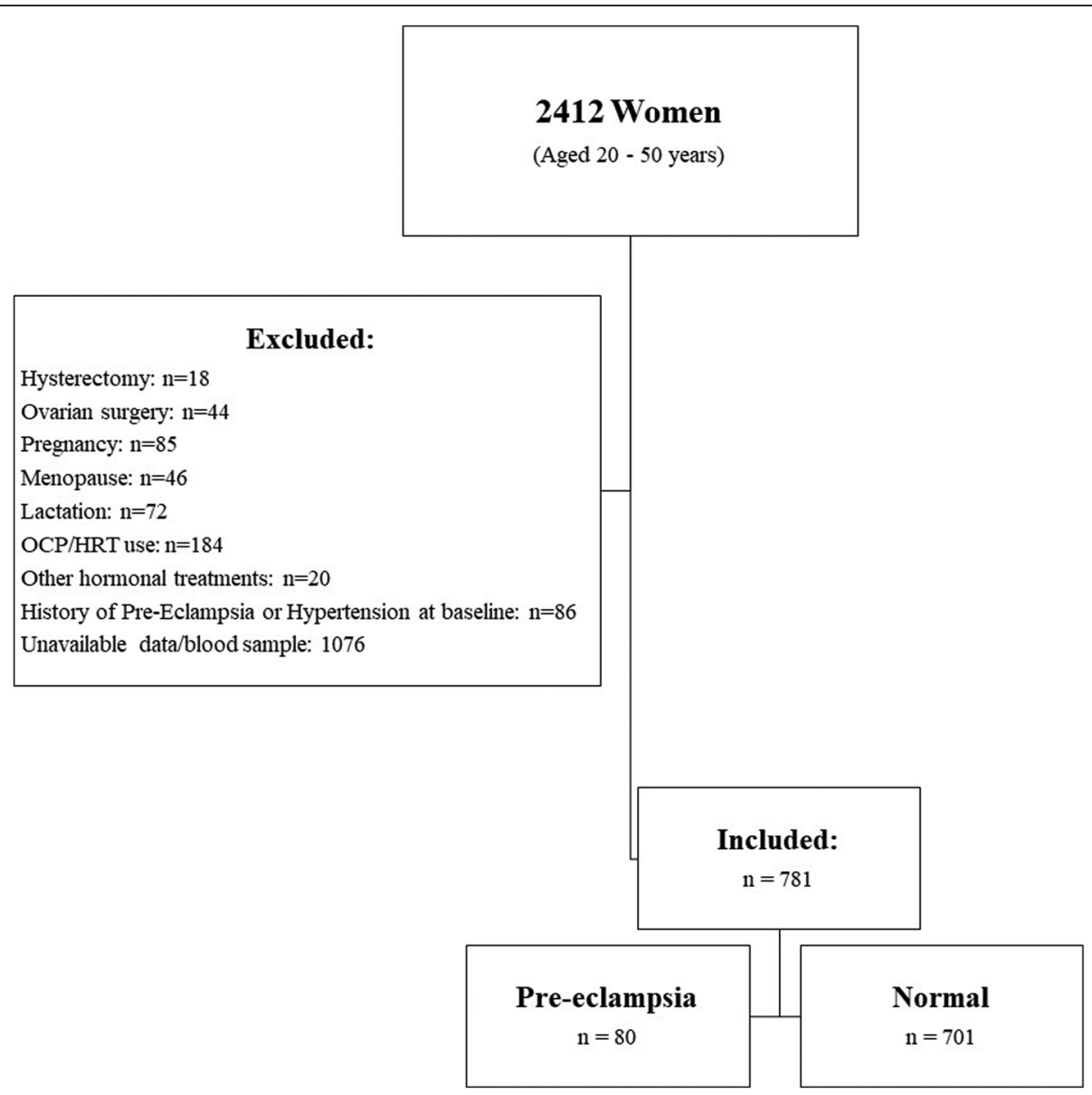

Fig. 1 Summary of case recruitment for the study

criteria [24]. In our country, PE diagnosis is as a part of routine prenatal care that is determined based on the standard definition of onset of a BP level $\geq 140 / 90$ $\mathrm{mmHg}$ with proteinuria $>0.3 \mathrm{~g} / 24 \mathrm{~h}$ after 20 weeks' gestation. At the time of data collection, women were asked about their history of PE based on a specific validated self-reporting questionnaire [25]. For patients who have no accurate information about their PE diagnosis, we checked their summary from hospital records.

\section{Statistical analysis}

All continuous variables were checked for normality using the one-sample Kolmogorov-Smirnoff test, and expressed as mean \pm standard deviation, or median with inter-quartile range (IQ25-75). To normalize the distribution of $\mathrm{AMH}, \log$ transformation was used. Characteristics of women at the time of recruitment were compared between those experienced PE during follow-ups and those who did not experience (non-PE) using either two independent sample t-test or the Mann-Whitney U-test. The categorical variables, expressed as percentages, were compared using Pearson's $\chi^{2}$ test.
A Receiver Operating Characteristics (ROC) curve was used for assessing predictive power of AMH for event of $\mathrm{PE}$, and the Area Under Curve (AUC) was calculated. To explore the association between PE status and serum AMH levels linear regression analysis with censoring, based on the Buckley-James method (on log-transformed $\mathrm{AMH}$ ) was used and adjusted for the confounders such as smoking status (ever/never), BMI $(\mathrm{kg} / \mathrm{m} 2)$, SBP $(\mathrm{mmHg})$ and family history of hypertension (yes/no). If the AMH level was undetectable $(<.16 \mathrm{mg} / \mathrm{L})$, AMH values were censored [14]. To compare the potential nonlinear relationship between $\mathrm{AMH}$ and age/BMI between those who experienced and those who did not experience PE, fractional polynomial function was used; the relationship has been depicted graphically.

We also used pooled logistic regression to assess the association between dichotomous outcome variable PE and the time-dependent covariates as the data was interval censored and time to PE was not known, and to calculate odds ratios [26]. This model treats every interval as a mini follow up study, pools the observations of all intervals together into one pooled sample and does a 
Table 1 Characteristics of Participants in women experienced preeclampsia during follow-ups with those not experienced

\begin{tabular}{|c|c|c|c|}
\hline & \multirow{2}{*}{$\begin{array}{l}\mathrm{PE} \\
N=80\end{array}$} & \multirow{2}{*}{$\begin{array}{l}\text { Non-PE } \\
N=701\end{array}$} & \multirow[t]{2}{*}{$P$-Value } \\
\hline & & & \\
\hline Age at $\mathrm{AMH}$ measurement (year), mean $\pm \mathrm{SD}$ & $36.9 \pm 6.7$ & $37.6 \pm 6.5$ & 0.32 \\
\hline $\mathrm{BMI}\left(\mathrm{Kg} / \mathrm{m}^{2}\right)$, mean $\pm \mathrm{SD}$ & $27.9 \pm 4.3$ & $27.1 \pm 4.4$ & 0.10 \\
\hline Waist circumference $(\mathrm{cm})$, mean \pm SD & $89.7 \pm 10.9$ & $86.0 \pm 10.2$ & 0.003 \\
\hline WHR, median (IQr) & $0.8(0.8-0.9)$ & $0.8(0.8-0.9)$ & 0.08 \\
\hline Parity, mean \pm SD & $2.5 \pm 1.2$ & $2.6 \pm 1.3$ & 0.44 \\
\hline Number of abortions, mean \pm SD & $0.5 \pm 0.9$ & $0.4 \pm 0.7$ & 0.35 \\
\hline Higher education, n (\%) & $43(53.8 \%)$ & $356(50.8 \%)$ & 0.61 \\
\hline Ever Smoker, n (\%) & $9(11.3 \%)$ & $31(4.4 \%)$ & 0.01 \\
\hline $\mathrm{SBP}(\mathrm{mmHg})$, mean $\pm \mathrm{SD}$ & $114.0 \pm 11.8$ & $109.1 \pm 10.4$ & 0.001 \\
\hline $\mathrm{DBP}(\mathrm{mmHg})$, mean $\pm \mathrm{SD}$ & $76.9 \pm 7.4$ & $73.6 \pm 7.6$ & $<0.001$ \\
\hline Cholesterol (mg/L), mean $\pm \mathrm{SD}$ & $198.8 \pm 37.1$ & $195.4 \pm 3.7$ & 0.40 \\
\hline $\operatorname{Tg}(\mathrm{mg} / \mathrm{dL})$, median (IQr) & $132(93-194)$ & $114(83.5-162)$ & 0.06 \\
\hline $\mathrm{LDL}(\mathrm{mg} / \mathrm{L})$, mean $\pm \mathrm{SD}$ & $127.9 \pm 31.2$ & $125.2 \pm 30.1$ & 0.46 \\
\hline $\mathrm{HDL}(\mathrm{mg} / \mathrm{L})$, mean $\pm \mathrm{SD}$ & $42.5 \pm 8.5$ & $44.0 \pm 10.1$ & 0.19 \\
\hline Fasting BG $(\mathrm{g} / \mathrm{dl})$, mean $\pm \mathrm{SD}$ & $96.9 \pm 41.0$ & $90.3 \pm 20.5$ & 0.16 \\
\hline AMH level (mg/L), median (IQr) & $1.05(0.36-2.2)$ & $0.85(0.28-2.1)$ & 0.53 \\
\hline Non-detectable AMH levels, n (\%) & $13(16.3)$ & $114(16.3)$ & 0.90 \\
\hline
\end{tabular}

$P E$ experienced preeclampsia during follow ups; non-PE not experienced preeclampsia during follow ups; $A M H$ anti-mullerian hormone; $B M I$ body mass index; $W H R$ waist to hip ratio; SBP systolic blood pressure; $D B P$ diastolic blood pressure; $T g$ triglyceride; $L D L$ low density lipoprotein; $H D H$ high density lipoprotein; $B G$ blood glucose

Higher education was defined as equivalent of the completion of $\mathrm{K}-12$ or above

Variables are reported as mean \pm SD (Student $t$ test), median(IQr) (Mann-Whitney $U$ test) or $n(\%)$ Chi square test as appropriate

Bold values are considered significant

logistic regression on the pooled dataset; it has been adjusted for above mentioned confounders.

We used Stata Statistical Software (Release 14. College Station, TX: Stata Corp LP) and a $P$-value of $<0.05$ was considered statistically significant.

\section{Results}

Baseline characteristics of the study population are summarized in Table 1. Mean WC, SBP, DBP, and smoking habit were different between the 2 groups (Table 1).

During follow-ups PE occurred in 23 (11.1\%), 12 (6.4\%), 26 (13.3\%) and 19 (10\%) women in the 1st, 2nd, 3rd and 4th quartiles of age-specific AMH, respectively $(P=0.16)$.

The median and inter-quartile range of serum AMH level was $1.05(0.36-2.2) \mathrm{mg} / \mathrm{L}$ in women who experience PE, compared with $0.85(0.28-2.1) \mathrm{mg} / \mathrm{L}$ in women with normotensive pregnancies $(P=0.53)$.

On the basis of the Buckley-James regression method, the unadjusted relative difference in AMH levels comparing $\mathrm{PE}$ with non-PE groups was 0.06 with $95 \% \mathrm{CI}$ ($0.26,0.14)$; in other words, we determined that the baseline AMH levels of women who experienced PE did not differ significantly from those of women who did not experienced PE women with experienced PE, even after adjustments for age, BMI, smoking status, and family history of hypertension (Table 2).

According to the pooled logistic regression analysis, the effects of age-specific AMH quartiles on PE progression (adjusted for age, BMI, smoking status, and family history of hypertension) were not significant $\left(\mathrm{OR}_{1 \mathrm{st} \text { vs } 4 \text { th }}\right.$ : 1.5, $P$-value: 0.1, CI: $(0.9,2.4)$ ) (Table 3). Neither did ROC

Table 2 Association between preeclampsia status and baseline serum concentration of AMH levels using the Buckley-James $\operatorname{method}^{\mathrm{a}}(n=781)$

\begin{tabular}{ll}
\hline & $\begin{array}{l}\text { Relative difference in } \\
\mathrm{AMH},(\mathrm{mg} / \mathrm{L})(95 \% \mathrm{Cl})\end{array}$ \\
\hline PE Vs. non-PE & $0.06(-0.26,0.14)$ \\
Adjusted for age(year) & $0.01(-0.26,0.24)$ \\
Adjusted for age(year) and BMI $\left(\mathrm{kg} / \mathrm{m}^{2}\right)$ & $0.0(-0.25,0.25)$ \\
Adjusted for age(year), BMI $\left(\mathrm{kg} / \mathrm{m}^{2}\right)$ and & $0.01(-0.26,0.24)$
\end{tabular}

smoking status(ever/never)

Adjusted for age(year), BMI(kg/m2), smoking status (ever/never)and family history of hypertension(yes/no)

$P E$ experienced preeclampsia during follow ups; non-PE not experienced preeclampsia during follow ups; $B M I$ body mass index; $A M H$ anti-mullerian hormone

${ }^{a}$ Buckley-James method was used as linear regression analysis with censoring on log-transformed $\mathrm{AMH}$, if the AMH level was undetectable $(<.16 \mathrm{mg} / \mathrm{L}), \mathrm{AMH}$ values were censored 
Table 3 Adjusted pooled logistic regression analysis for progression of preeclampsia according to age-specific $\mathrm{AMH}$ quartiles

\begin{tabular}{lll}
\hline & aOR $(95 \% \mathrm{Cl})$ & $p$-value \\
\hline age-specific AMH & & \\
1st Quartile & $1.48(0.89,2.48)$ & 0.1 \\
2nd Quartile & $1.02(0.74-2.54)$ & 0.8 \\
3rd Quartile & $0.97(0.54-1.74)$ & 0.9 \\
4th Quartile & 1(reference group) & \\
\hline
\end{tabular}

$a O R$ adjusted odds ratio; $A M H$ anti-mullerian hormone; $B M I$ body mass index ${ }^{a}$ Age-specific AMH was calculated using the exponential-normal three-parameter model

Model was adjusted for smoking status, BMI, systolic blood pressure and family history of hypertension

analysis of age-specific AMH show any predictive performance for PE; AUC $(95 \% \mathrm{CI})$ was $0.54(0.45-0.63)(P=$ 0.40) (Fig. 2). Decrease in AMH levels, with increasing age and BMI, was not statistically different between the two groups (PE and non-PE) (Figs. 3.a and 3.b).

\section{Discussion}

In this study we found that ovarian reserve status, estimated using AMH serum concentrations may not be useful in the prediction of increased risk for subsequent PE.

Previous animal studies have introduced AMH as one of the factors involved in the inhibition of primary follicle growth and its response to FSH [27-29]. Although the exact pathophysiology of AMH in human ovarian aging is still a matter of debate, it is well documented that $\mathrm{AMH}$ is an appropriate biomarker of ovarian reserve and function; as a result lower AMH may be associated with an increase in vascular risks and events [4, 30-36]. Koninger et al. showed that AMH levels decrease during pregnancy [37]; in 2015; they also confirmed that this decline is real and that it is not due to interfering complement activation with the conventional assay [38].

Yarde et al. demonstrated a lower AMH level in women with a history of preeclampsia, suggesting that both $\mathrm{PE}$ and premature ovarian aging are manifestations of underlying vascular dysfunction [14]; however, the researchers in this study used $\mathrm{AMH}$, not age-specific $\mathrm{AMH}$, in their analysis; previous investigators preferred using age-specific $\mathrm{AMH}$, rather than $\mathrm{AMH}$, as a better predictor of ovarian reserve status [39]. Similarly, Shand et al., in a retrospective study found that women with a very low AMH $(1.5 \mathrm{pmol} / \mathrm{L})$ in early pregnancy may have a slightly increased risk for subsequent PE [15]. However, interpretation of these data is difficult, since women with significantly lower levels of AMH (and thus potentially at highest risk for subsequent pregnancy-related hypertensive disease) would also be less likely to conceive, thus potentially being excluded from the population on their bases.

Finally, a prospective study by Tokmak et al. in 2015 reported maternal serum AMH to be lower in PE patients than in those with normal pregnancies, albeit with low sensitivity and specificity $(\mathrm{AUC}=0.59$, sensitivity $=$

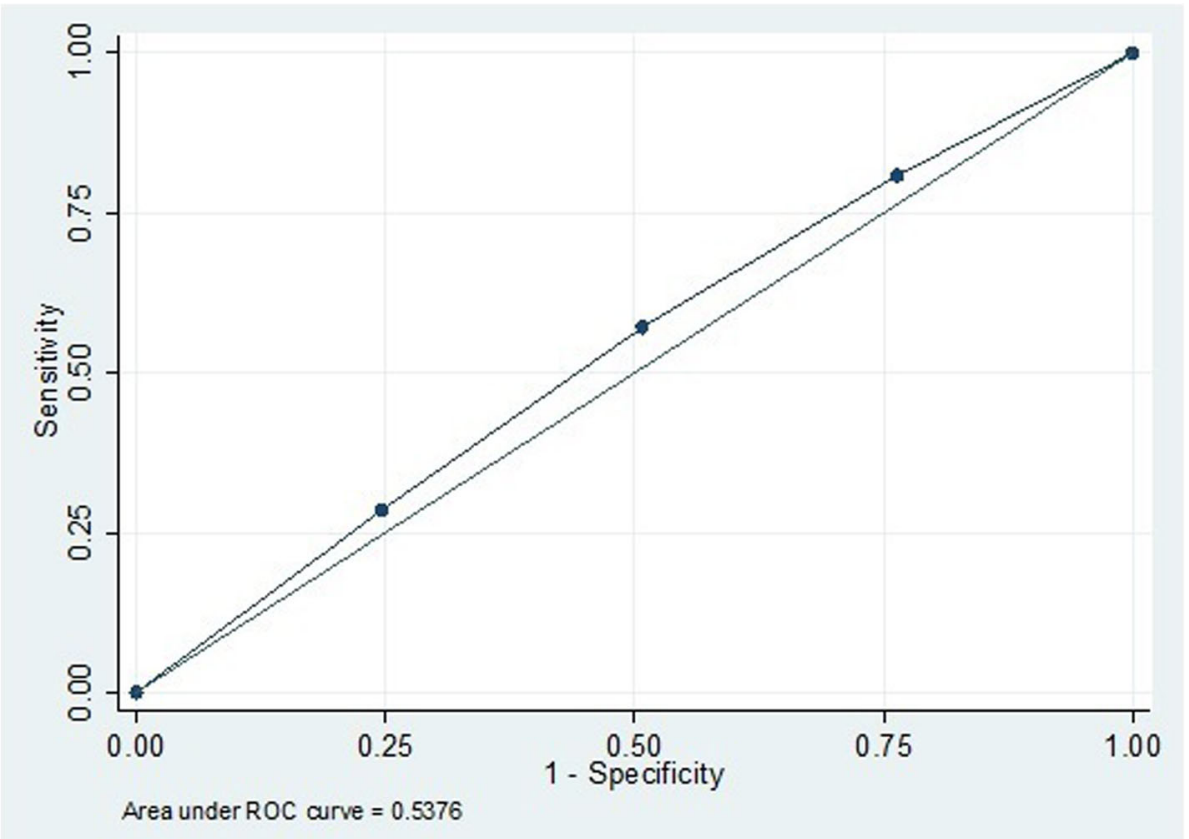

Fig. 2 ROC curve for age-specific AMH as a predictor of preeclampsia 


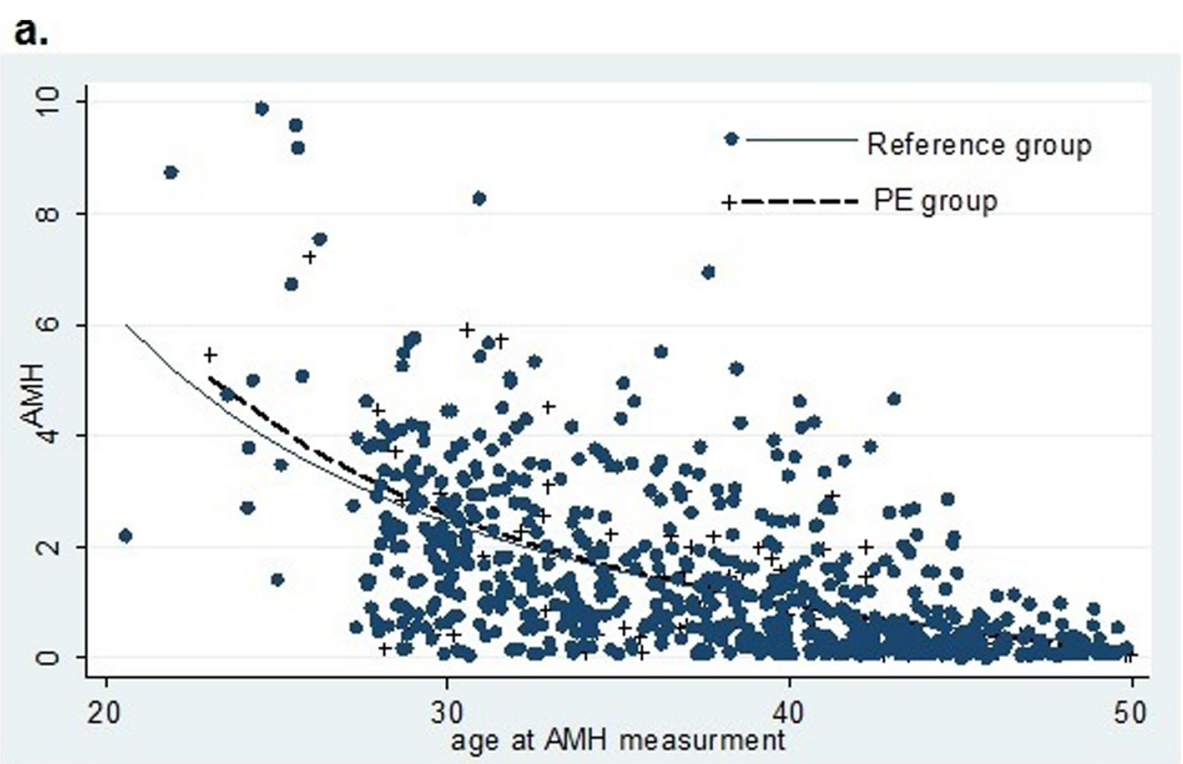

b.

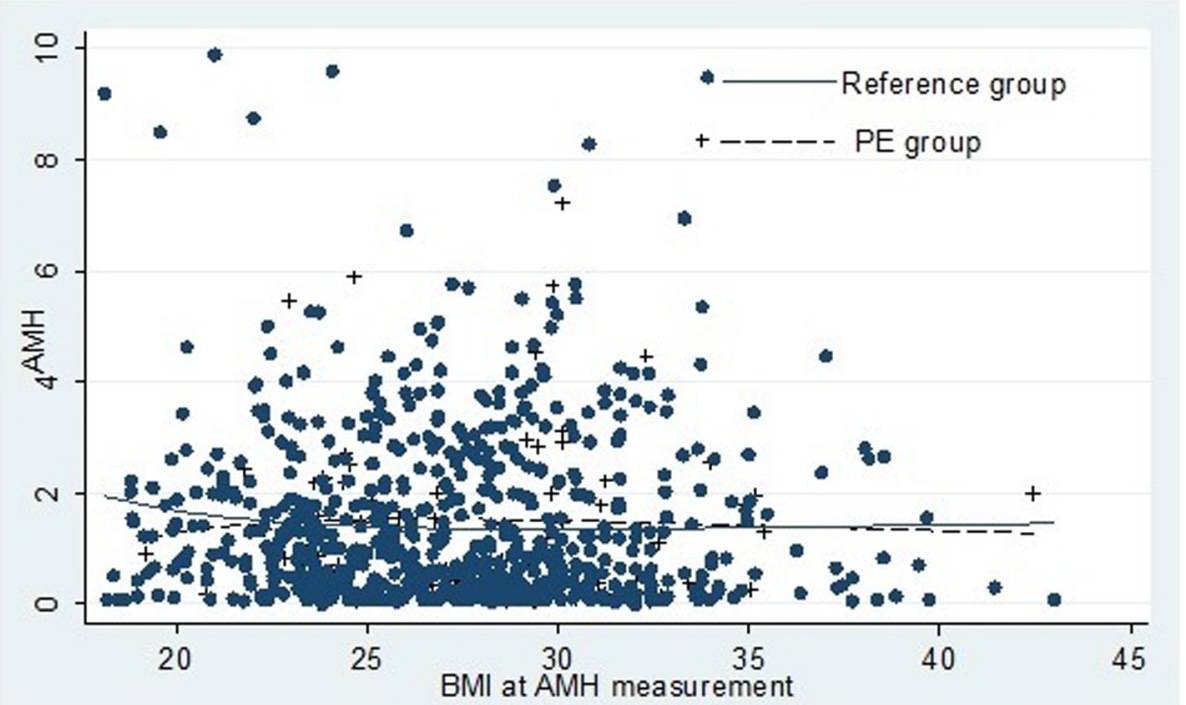

Fig. 3 Age related (a) and BMl related (b) AMH in women with PE compared with that of a reference group. The serum AMH level is plotted on a logarithmic scale

67.4 and specificity $=47.1 \%$ ) for the prediction of $\mathrm{PE}$ [16]; they also used the absolute maternal $\mathrm{AMH}$, rather than the age-specific AMH.

In contrast, Birdir, et al. investigated the AMH levels at 11-13 weeks of gestation in prediction of $\mathrm{PE}$ and concluded that maternal serum AMH is not an effective predictor of PE in pregnancy [40]. Since AMH levels during pregnancy are often variable [37, 40], Since AMH levels during pregnancy are often variable $[35,38]$, which could influence relationship between $\mathrm{AMH}$ and $\mathrm{PE}$, we assessed this association in non-pregnant women. However, similar to Birdir study findings, the current study did not show any association between AMH and PE. We concluded that while a sizeable body of evidence exists regarding the relationship of $\mathrm{AMH}$ and the development of PE, most studies using age-specific AMH levels have shown no association, or a weak association.

Our study has number of strengths. It is unique in that it uses unselected pregnant women in a subset of a cohort study with a long-term follow-up. Also, in our analyses we used 'age-specific' AMH, and our method for identification of age-specific AMH was precise. As we have shown, among all available models, our model (exponential-normal (EN) three-parameter model) provided a good fit, since the normal plot of the Z-scores from our model appears reasonably linear; moreover, in our model about 
$10 \%$ of the observations lie above the 90th percentile or below the 10th percentile. Another strength of our study was that laboratory measurements were done simultaneously at the same laboratory by the same person in order to minimize intra-assay variability in the data. Since all blood samples were centrifuged within 30-45 min of collection and stored at -80 degrees $\mathrm{C}$, AMH molecular instability was not an issue in this study [34].

There were also some limitations to our study; one potential limitation was that we had only one measurement of AMH per case in our cohort. Another limitation was that due to design of the study we were unable to discuss causality and effect. We acknowledge that recall bias in self-reporting of preeclampsia might be another limitation; however, we see no reason to believe that there would be a differential recall bias among women based on their AMH levels; a similar rate of recall error would be expected in both groups and this would not impact our results. Moreover, there is a body of literature that suggests the reliability of self-reporting $\mathrm{PE}$ as a variable in epidemiologic studies using standard questionnaires [18, 19]. The time interval between AMH measurement and occurrence of pregnancy or PE was not collected in details, as a result we are unable to adjust our results for this time interval; despite that a single AMH measurement can precisely identify the ovarian reserve status of subjects as its level remains almost constant from one cycle to another and has a high intraclass correlation coefficient as a result of which only one measurement provides a reliable estimate of its mean in each woman [41]. Finally, since we had not measured pre-conception $\mathrm{AMH}$, given the potential decline in fertility rates of women with lower AMH levels and any possible changes in these levels overtime, our values were not entirely reflective of levels preceding the index pregnancy and need to be interpreted cautiously.

\section{Conclusions}

Age-specific AMH may not be a suitable marker for prediction of PE. Further longitudinal studies, considering pre-conception measurement of $\mathrm{AMH}$, are recommended for better interpretation of the association between ovarian reserve status and PE.

\footnotetext{
Abbreviations

AMH: Anti-Mullerian Hormone; apo B: Apolipoprotein B; AUC: Area under curve; BMI: Body mass index; CVs: COEFFICIENTS of Variations; DBP: Diastolic Blood Pressure; ElA: Enzyme immunoassay; EN: Exponential-normal; FPG: Fasting plasma glucose; HDL-C: High-density Lipoprotein Cholesterol; LDL-C: Low-density Lipoprotein Cholesterol; PE: Pre-Eclampsia; SBP: Systolic Blood Pressure; TC: Total Cholesterol; TG: Triglyceride; TLGS: Tehran Lipid and Glucose Study; WC: Waist Circumference
}

\section{Acknowledgements}

Authors are indebted to each of the study participants for the substantial time and effort contributed to this study. Acknowledgments are also due to the research staff at the Tehran Lipid and Glucose Study. We would like to acknowledge Ms. Niloofar Shiva, an academic faculty member of the
Research Institute for Endocrine Sciences (RIES), for critical editing of English grammar and syntax of the manuscript.

\section{Rights and permissions}

This study approved by the ethics committee of the Research Institute for Endocrine Sciences and all administrative permissions obtained to use data from the Tehran Lipid and Glucose Study (TLGS).

\section{Authors' contributions}

HE and FRT contributed to the study design and execution, data analysis, manuscript drafting and critical discussion. MR contributed to the data analysis, manuscript drafting and critical discussion. MAM contributed to the data analysis and manuscript drafting. SAM and AAS contributed to manuscript drafting and critical discussion. FA contributed to the study design and execution and manuscript drafting. All authors read and approved the final manuscript.

\section{Funding}

This research did not receive any specific grant from funding agencies in the public, commercial, or not-for-profit sectors.

\section{Availability of data and materials}

The dataset used during the current study is available from the corresponding author on reasonable request.

Ethics approval and consent to participate

This study was approved by the ethics committee of the Research Institute for Endocrine Sciences (IR.SBMU.ENDOCRINE.REC.1398.009) and a written informed consent was obtained from all subjects before initiation of the study.

\section{Consent for publication}

Not applicable.

\section{Competing interests}

The authors declare that they have no competing interests.

\section{Author details}

${ }^{1}$ Department of Obstetrics and Gynecology, Baylor College of Medicine, Houston, TX, USA. ${ }^{2}$ Reproductive Endocrinology Research Center, Research Institute for Endocrine Sciences, Shahid Beheshti University of Medical Sciences, 24 Parvaneh, Yaman Street, Velenjak, P.O. Box:19395-4763, Tehran 1985717413, Iran. ${ }^{3}$ Department of Epidemiology and Biostatistics, School of Public Health, Tehran University of Medical Sciences, Tehran, Iran. ${ }^{4}$ Endocrine Research Center, Research Institute for Endocrine Sciences, Shahid Beheshti University of Medical Sciences, Tehran, Iran.

Received: 26 September 2019 Accepted: 5 November 2019

Published online: 21 November 2019

\section{References}

1. Sutton ALM, Harper LM, Tita ATN. Hypertensive disorders in pregnancy. Obstet Gynecol Clin N Am. 2018;45(2):333-47.

2. Magee LA, Pels A, Helewa M, Rey E, von Dadelszen P. Diagnosis, evaluation, and management of the hypertensive disorders of pregnancy: executive summary. J Obstet Gynaecol Can. 2014;36(7):575-6.

3. von Dadelszen P, Magee LA. Pre-eclampsia: an update. Curr Hypertens Rep. 2014;16(8):454

4. Feyereisen E, Mendez Lozano DH, Taieb J, Hesters L, Frydman R, Fanchin R. Anti-Mullerian hormone: clinical insights into a promising biomarker of ovarian follicular status. Reprod BioMed Online. 2006;12(6):695-703.

5. de Vet A, Laven JS, de Jong FH, Themmen AP, Fauser BC. Antimullerian hormone serum levels: a putative marker for ovarian aging. Fertil Steril. 2002;77(2):357-62.

6. van Rooij IA, Broekmans FJ, Scheffer GJ, Looman CW, Habbema JD, de Jong $\mathrm{FH}$, et al. Serum antimullerian hormone levels best reflect the reproductive decline with age in normal women with proven fertility: a longitudinal study. Fertil Steril. 2005;83(4):979-87.

7. Lambalk CB, van Disseldorp J, de Koning CH, Broekmans FJ. Testing ovarian reserve to predict age at menopause. Maturitas. 2009;63(4):280-91. 
8. Tehrani FR, Solaymani-Dodaran M, Tohidi M, Gohari MR, Azizi F. Modeling age at menopause using serum concentration of anti-mullerian hormone. J Clin Endocrinol Metab. 2013;98(2):729-35.

9. de Kat AC, Verschuren WM, Eijkemans MJ, van der Schouw YT, Broekmans FJ. The association of low ovarian reserve with cardiovascular disease risk: a cross-sectional population-based study. Hum Reprod. 2016;31(8):1866-74.

10. Tehrani FR, Erfani H, Cheraghi L, Tohidi M, Azizi F. Lipid profiles and ovarian reserve status: a longitudinal study. Hum Reprod. 2014;29(11):2522-9.

11. de Kat AC, Broekmans FJ, Laven JS, van der Schouw YT. Anti-Mullerian hormone as a marker of ovarian reserve in relation to cardio-metabolic health: a narrative review. Maturitas. 2015;80(3):251-7.

12. de Kat AC, Verschuren WM, Eijkemans MJ, Broekmans FJ, van der Schouw YT. Anti-Mullerian hormone trajectories are associated with cardiovascular disease in women: results from the Doetinchem cohort study. Circulation. 2017;135(6):556-65.

13. Kim C, Pan Y, Braffett BH, Arends VL, Steffes MW, Wessells H, et al. AntiMullerian hormone and its relationships with subclinical cardiovascular disease and renal disease in a longitudinal cohort study of women with type 1 diabetes. Women's Midlife Health. 2017;3:5.

14. Yarde F, Maas AH, Franx A, Eijkemans MJ, Drost JT, van Rijn BB, et al. Serum $\mathrm{AMH}$ levels in women with a history of preeclampsia suggest a role for vascular factors in ovarian aging. J Clin Endocrinol Metab. 2014;99(2):579-86.

15. Shand AW, Whitton K, Pasfield A, Nassar N, McShane M, Han X, et al. Evaluation of anti-Mullerian hormone in the first trimester as a predictor for hypertensive disorders of pregnancy and other adverse pregnancy outcomes. Aust N Z J Obstet Gynaecol. 2014;54(3):244-9.

16. Tokmak A, Guney G, Aksoy RT, Guzel Al, Topcu HO, Kececioglu TS, et al. May maternal anti-mullerian hormone levels predict adverse maternal and perinatal outcomes in preeclampsia? J Mater Fetal Neonat Med. 2015; 28(12):1451-6.

17. Azizi F, Rahmani M, Emami H, Mirmiran P, Hajipour R, Madjid M, et al. Cardiovascular risk factors in an Iranian urban population: Tehran lipid and glucose study (phase 1). Sozial- und Praventivmedizin. 2002;47(6):408-26.

18. Diehl CL, Brost BC, Hogan MC, Elesber AA, Offord KP, Turner ST, et al. Preeclampsia as a risk factor for cardiovascular disease later in life: validation of a preeclampsia questionnaire. Am J Obstet Gynecol. 2008; 198(5):e11-3.

19. Klemmensen AK, Olsen SF, Osterdal ML, Tabor A. Validity of preeclampsiarelated diagnoses recorded in a national hospital registry and in a postpartum interview of the women. Am J Epidemiol. 2007:166(2):117-24.

20. Altman DG, Chitty LS. Charts of fetal size: 1. Methodology. Br J Obstet Gynaecol. 1994;101(1):29-34.

21. Royston P, Wright EM. How to construct 'normal ranges' for fetal variables. Ultrasound Obstet Gynecol. 1998;11(1):30-8.

22. Royston P, Wright EM. Goodness-of-fit statistics for age-specific reference intervals. Stat Med. 2000;19(21):2943-62.

23. Tehrani FR, Mansournia MA, Solaymani-Dodaran M, Azizi F. Age-specific serum anti-Mullerian hormone levels: estimates from a large populationbased sample. Climacteric. 2014;17(5):591-7.

24. Brown MA, Lindheimer MD, de Swiet M, Van Assche A, Moutquin JM. The classification and diagnosis of the hypertensive disorders of pregnancy: statement from the International Society for the Study of Hypertension in Pregnancy (ISSHP).Hypertens Pregnancy. 2001;20(1).

25. Amiri M, Tehrani FR, Rahmati M, Behboudi-Gandevani S, Azizi F. Changes over-time in blood pressure of women with preeclampsia compared to those with normotensive pregnancies: a 15 year population-based cohort study. Pregnancy Hypertension. 2019;17:94-9.

26. D'Agostino RB, Lee ML, Belanger AJ, Cupples LA, Anderson K, Kannel WB. Relation of pooled logistic regression to time dependent cox regression analysis: the Framingham heart study. Stat Med. 1990;9(12):1501-15.

27. Durlinger AL, Gruijters MJ, Kramer P, Karels B, Ingraham HA, Nachtigal MW, et al. Anti-Mullerian hormone inhibits initiation of primordial follicle growth in the mouse ovary. Endocrinology. 2002;143(3):1076-84

28. Durlinger AL, Gruijters MJ, Kramer P, Karels B, Kumar TR, Matzuk MM, et al. Anti-Mullerian hormone attenuates the effects of FSH on follicle development in the mouse ovary. Endocrinology. 2001;142(11):4891-9.

29. Carlsson IB, Scott JE, Visser JA, Ritvos O, Themmen AP, Hovatta O. AntiMullerian hormone inhibits initiation of growth of human primordial ovarian follicles in vitro. Hum Reprod. 2006;21(9):2223-7.

30. Visser JA, de Jong FH, Laven JS, Themmen AP. Anti-Mullerian hormone: a new marker for ovarian function. Reproduction. 2006;131(1):1-9.
31. Anderson EL, Fraser A, McNally W, Sattar N, Lashen H, Fleming R, et al. Antimullerian hormone is not associated with cardiometabolic risk factors in adolescent females. PLoS One. 2013;8(5):e64510.

32. Atsma F, Bartelink ML, Grobbee DE, van der Schouw YT. Postmenopausal status and early menopause as independent risk factors for cardiovascular disease: a meta-analysis. Menopause. 2006;13(2):265-79.

33. van der Schouw YT, van der Graaf Y, Steyerberg EW, Eijkemans JC, Banga JD. Age at menopause as a risk factor for cardiovascular mortality. Lancet. 1996;347(9003):714-8.

34. Hu FB, Grodstein F, Hennekens CH, Colditz GA, Johnson M, Manson JE, et al. Age at natural menopause and risk of cardiovascular disease. Arch Intern Med. 1999;159(10):1061-6.

35. Berenson GS, Srinivasan SR, Bao W, Newman WP 3rd, Tracy RE, Wattigney WA. Association between multiple cardiovascular risk factors and atherosclerosis in children and young adults. The Bogalusa heart study. N Engl J Med. 1998;338(23):1650-6.

36. Chu MC, Rath KM, Huie J, Taylor HS. Elevated basal FSH in normal cycling women is associated with unfavourable lipid levels and increased cardiovascular risk. Hum Reprod. 2003;18(8):1570-3.

37. Koninger A, Kauth A, Schmidt B, Schmidt M, Yerlikaya G, Kasimir-Bauer S, et al. Anti-Mullerian-hormone levels during pregnancy and postpartum. Reprod Biol Endocrinol. 2013;11:60.

38. Koninger A, Schmidt B, Mach P, Damaske D, Niessen S, Kimmig R, et al. Anti-Mullerian-hormone during pregnancy and peripartum using the new Beckman coulter AMH gen II assay. Reprod Biol Endocrinol. 2015;13:86.

39. Ramezani Tehrani F, Mansournia MA, Solaymani-Dodaran M, Steyerberg E, Azizi F. Flexible parametric survival models built on age-specific antimullerian hormone percentiles are better predictors of menopause. Menopause. 2016;23(6):676-81.

40. Birdir C, Fryze J, Vasiliadis H, Nicolaides KH, Poon LC. Maternal serum antiMullerian hormone at 11-13 weeks' gestation in the prediction of preeclampsia. J Matern Fetal Neonatal Med. 2015;28(8):865-8.

41. La Marca $\mathrm{A}$, Volpe $\mathrm{A}$. Anti-Müllerian hormone $(\mathrm{AMH})$ in female reproduction: is measurement of circulating AMH a useful tool? Clin Endocrinol. 2006; 64(6):603-10.

\section{Publisher's Note}

Springer Nature remains neutral with regard to jurisdictional claims in published maps and institutional affiliations.
Ready to submit your research? Choose BMC and benefit from:

- fast, convenient online submission

- thorough peer review by experienced researchers in your field

- rapid publication on acceptance

- support for research data, including large and complex data types

- gold Open Access which fosters wider collaboration and increased citations

- maximum visibility for your research: over $100 \mathrm{M}$ website views per year

At $\mathrm{BMC}$, research is always in progress.

Learn more biomedcentral.com/submissions 